\title{
PEMAHAMAN BANK INDONESIA DAN ANGGOTA KELOMPOK TANI MARGO MULYO TERHADAP PROGRAM LOCAL ECONOMIC DEVELOPMENT DI KECAMATAN SAMIGALUH KABUPATEN KULON PROGO
}

\author{
The Central Bank Of The Republic Of Indonesia And Margo Mulyo Farmer \\ Group's Comprehension Through Local Economic Development Program At \\ Samigaluh District Kulon Progo Regency
}

\author{
Muhammad Hanif Sudarmadi*, Eko Murdiyanto, Daru Retnowati \\ Program Studi Agribisnis Fakultas Pertanian \\ Universitas Pembangunan Nasional "Veteran" Yogyakarta \\ Jl. SWK 104, Condongcatur, Kecamatan Depok, Kabupaten Sleman, \\ Yogyakarta, Indonesia \\ *Email korespondensi : mhanifsud@gmail.com
}

Diterima tanggal : 28 Februari 2020 ; Disetujui tanggal 11 Maret 2020

\begin{abstract}
The research aimed to study the Central Bank of The Republic of Indonesia and farmer group member's comprehension about Local Economic Development program. It was qualitatively research with case study method and took informants purposively It was qualitative research with case study method and took informants purposively which were MSME Consultant of Bank Indonesia DIY, Assistant of Policy Coordination and Communication Manager Bank Indonesia DIY, Assistant of MSME Development Manager Bank Indonesia DIY, production and processing Section of Margo Mulyo farmer group, head of Margo Mulyo farmer group, secretary of Margo Mulyo farmer group and Margo Mulyo farmer group member. Data gathering technique was observation, interview, and documentation, while the data validation technique obtained by triangulation of data collection technique and the data analyzing technique was data reduction, data display, and conclusion drawing. The results of this research indicated that the Central Bank of The Republic of Indonesia comprehension about Local Economic Development program was on beyond compliance whereas farmer group member comprehension about Local Economic Development program was considered as a grant program. The suggestion from this research is Local Economic Development have to maintained their comprehension of Local Economic Development program and Margo Mulyo farmer group member have to increased their comprehension about Local Economic Development program so Margo Mulyo farmer group would grow bigger and more independent.
\end{abstract}

Keywords: Empowerment, Farmer Group Members, Local Economic Development, the Central Bank of The Republic of Indonesia, 


\begin{abstract}
ABSTRAK
Penelitian ini bertujuan untuk mengkaji pemahaman Bank Indonesia dan anggota kelompok tani Margo Mulyo terhadap program Local Economic Development. Penelitian ini merupakan penelitian kualitatif dengan metode pelaksanaan studi kasus dan pengambilan informan secara purposif dengan informan Konsultan UMKM Bank Indonesia DIY, Asisten Manajer Fungsi Koordinasi dan Komunikasi Kebijakan Bank Indonesia DIY, Asisten Manajer Fungsi Pelaksanaan Pengembangan UMKM Bank Indonesia DIY, Pengurus Sekretariat Kelompok Tani Margo Mulyo, Ketua Kelompok Tani Margo Mulyo, Sekretaris Kelompok Tani Margo Mulyo dan Anggota Kelompok Tani Margo Mulyo sebagai pihak yang terlibat dalam program Local Economic Development. Teknik pengumpulan data yang digunakan adalah observasi, wawancara dan dokumentasi. Keabsahan data yang diperoleh diuji dengan triangulasi teknik pengumpulan data dan analisis data dilakukan menggunakan reduksi data, penyajian data dan penarikan kesimpulan. Hasil penelitian ini memberikan kesimpulan bahwa Pemahaman Bank Indonesia terhadap program Local Economic Development ini sudah pada tingkatan beyond compliance sedangkan anggota kelompok tani memahami program Local Economic Development sebagai program hibah. Saran dari penelitian tersebut adalah Bank Indonesia mempertahankan pemahaman mengenai program Local Economic Development dan anggota Kelompok Tani Margo Mulyo sebaiknya meningkatkan pemahaman terhadap program Local Economic Development sehingga dapat meningkatkan kemandirian kelompok tani.
\end{abstract}

Kata Kunci: Bank Indonesia, Kelompok Tani, Local Economic Development Pemberdayaan

\title{
PENDAHULUAN
}

Kelompok Tani Margo Mulyo berlokasi di Pedukuhan Madigondo, Desa Sidoharjo, Kecamatan Samigaluh, Kabupaten Kulon Progo, Daerah Istimewa Yogyakarta, terbentuk pertama kali pada 17 April 1977 namun secara administratif baru terbentuk pada tahun 2003, dengan nomor register atau nomor hukum 03/SDH/IX/2003. Kelompok Tani Margo Mulyo ini dibentuk untuk mewadahi para petani dapat berkembang lebih baik lagi, karena sebelum Kelompok Tani Margo Mulyo terbentuk sudah banyak tawaran-tawaran bantuan pemberdayaan masyarakat dari PPL (Penyuluh Pertanian Lapangan) dan dari dinas terkait namun karena belum terbentuknya suatu Kelompok Tani sehingga para petani di Pedukuhan Madigondo tidak bisa mendapatkan akses dana dari pemerintah. Namun seiring berjalannya waktu, kegiatan yang dilakukan oleh 
Sudarmadi et.al., Pemahaman Bank Indonesia dan Anggota Kelompok Tani...

Kelompok Tani tersebut mengalami stagnansi kegiatan akibat menurunnya harga kopi sehingga menyebabkan menurunnya tugas pokok dan fungsi kelompok. Kemudian salah satu anggota dari Kelompok Tani Margo Mulyo berinisiatif mengembangkan kembali Kelompok Tani Margo Mulyo yang sempat lesu tersebut. Konsepnya yaitu membangun suatu wisata edukasi Kopi Menoreh .

Wisata edukasi kopi adalah sebuah program yang megintegrasikan konsep pertanian hulu hilir serta potensi wisata alam dalam satu program. Program tersebut bertujuan untuk mengaktifkan kembali kegiatan kelompok tani serta mengarahkan kegiatan pertanian pada usaha peningkatan kesejahteraan masyarakat dan anggota kelompok serta kelestarian kearifan lokal.

Bergerak dari konsep wisata edukasi Kopi Menoreh ini dan adanya relasi dengan lembaga pemerintahan yaitu Bank Indonesia (BI) kemudian perwakilan dari Kelompok Tani Margo Mulyo mempresentasikan konsep mengenai wisata edukasi Kopi Menoreh tersebut sehingga akhirnya BI tertarik untuk melakukan pendampingan pada anggota Kelompok Tani Margo Mulyo untuk pembangunan wisata edukasi Kopi Menoreh tersebut.

Melalui program sosial, BI juga berupaya meningkatkan kesadaran dan pemahaman masyarakat terhadap pelaksanaan tugas dan pencapaian tujuan Bank Indonesia. Pada tahun 2018 Anggota Kelompok Tani Margo Mulyo mendapatkan program Local Economic Development (LED) yang merupakan CSR Bank Indonesia yaitu PSBI (Program Sosial Bank Indonesia) sebagai wujud penerapan CSR Bank Indonesia bekerjasama dengan beberapa stakeholders untuk menangani secara langsung kegiatan di lapangan yaitu Dinas Pertanian dan Pangan, Badan Perencanaan Pembangunan Daerah (Bappeda), Lembaga Ilmu Pengetahuan Indonesia (LIPI), Badan Penyuluh Pertanian Kulon Progo dan Dinas Pariwisata Kulon Progo. Tujuan penelitian ini adalah mengkaji pemahaman Bank Indonesia dan anggota Kelompok Tani Margo Mulyo mengenai program LED. 
Jurnal Dinamika Sosial Ekonomi, 21 (1) : 1-14

\section{METODE PENELITIAN}

Lokasi penelitian berada di Kelompok Tani Margo Mulyo, Desa Sidoharjo, Kecamatan Samigaluh, Kabupaten Kulon Progo, Yogyakarta. Kelompok Tani Margo Mulyo merupakan kelompok tani yang diberdayakan oleh BI karena potensi alamnya yaitu Kopi Menoreh (kopi dengan aroma khas kakao). Waktu penelitian dilakukan dari bulan Juni sampai dengan Agustus 2019. Jenis penelitian yang digunakan adalah penelitian kualitatif dengan pendekatan studi kasus. Fokus penelitian yang diamati ialah proses pemberdayaan pada anggota Kelompok Tani Margo Mulyo melalui program LED dari BI DIY. Teknik penentuan informan dilakukan dengan cara purposive sampling, yaitu jenis sampling yang paling tepat dalam penelitian kualitatif. Penggunaan purposive sampling perlu disesuaikan dengan tujuan penelitian yang spesifik berdasarkan kriteria-kriteria atau kategorikategori partisipan yang dikehendaki peneliti sesuai dengan masalah, tujuan dan desain penelitian yang diterapkan (Bandur, 2016).

Subjek penelitian dalam penelitian ini adalah sumber informasi atau orang yang paling paham mengenai data yang dibutuhkan yaitu Konsultan UMKM Bank Indonesia DIY, Asisten Manajer fungsi koordinasi dan komunikasi kebijakan Bank Indonesia DIY, Asisten Manajer Fungsi Pelaksanaan Pengembangan UMKM Bank Indonesia DIY, Anggota Kelompok Tani Margo Mulyo, Pengurus Kesekretariatan Kelompok Tani Margo Mulyo atau Seksi Pengolahan Kelompok Tani Margo Mulyo, Ketua Kelompok Tani Margo Mulyo dan Sekretaris Kelompok Tani Margo Mulyo. Pemilihan informan tersebut dilakukan karena pihak-pihak tersebut terlibat dan mengetahui program $L E D$ tersebut.

Teknik pengumpulan data yang digunakan dalam penelitian kualitatif adalah observasi langsung, wawancara mendalam, dan dokumentasi (Sugiyono, 2016). Dalam penelitian ini untuk menguji keabsahan data menggunakan triangulasi sumber dan triangulasi waktu untuk menguji kredibilitas data. Pengujian keabsahan data dilakukan dengan cara mengecek data kepada beberapa sumber dan waktu yang berbeda (Sugiyono, 2016). Miles dan Huberman (1984) dalam Sugiyono (2016) mengemukakan bahwa akivitas dalam 
Sudarmadi et.al., Pemahaman Bank Indonesia dan Anggota Kelompok Tani...

analisis data kualitatif dilakukan secara interaktif dan berlangsung secara terus menerus sampai tuntas, sehingga datanya jenuh. Analisis data yang dilakukan berupa data reduction, data display, dan conclusion drawing/verification.

\section{HASIL DAN PEMBAHASAN}

\section{Pemahaman Bank Indonesia terhadap Program Local Economic Development}

Local Economic Development BI ini bertujuan untuk mengangkat potensi ekonomi lokal pada daerah yang dituju oleh BI. Sebelum menentukan penerima manfaat untuk program LED, BI melakukan need assessment terlebih dahulu untuk mengkaji pihak yang akan menerima program $L E D$ inihal ini sesuai dengan pernyataan Marthin, dkk (2010) yaitu substansi keberadaan prinsip tanggung jawab sosial dan lingkungan bagi perusahaan atau Corporate Social Responsibility (CSR), adalah dalam rangka memperkuat kemampuan perusahaan untuk beradaptasi dengan lingkungannya, komunitas dan stakeholder yang terkait dengannya, baik lokal, nasional, maupun global. Di dalam pengimplementasiannya, diharapkan agar unsur-unsur perusahaan, pemerintah dan masyarakat saling berinteraksi dan mendukung, supaya CSR dapat diwujudkan secara komprehensif, sehingga dalam pengambilan keputusan, menjalankan keputusan dan pertanggungjawabannya dapat dilaksanakan bersama.

Local Economic Development BI ini bertujuan untuk mengangkat potensi ekonomi lokal yaitu Kopi Menoreh dan sudah berlangsung sejak tahun 2018 dan direncanakan berakhir pada tahun 2020. Menurut Astri (2012) Program CSR yang berkelanjutan diharapkan dapat membantu menciptakan kehidupan masyarakat yang lebih sejahtera dan mandiri. Setiap kegiatan tersebut akan melibatkan semangat sinergi dari semua pihak secara terus menerus membangun dan menciptakan kesejahteraan dan kemandirian masyarakat. Pada tahun pertama pendampingan difokuskan pada aspek budidaya berupa bimbingan teknis (bimtek) budidaya kopi dan studi banding Puslit Koka Jember, kemudian berlanjut dengan kegiatan pada penguatan kelembagaan melalui kegiatan capacity building. Melalui proses pengolahan dan pengendalian mutu yang terstandar dan tepat maka kualitas bubuk Kopi Menoreh yang dihasilkan telah memenuhi standar tentang 
Jurnal Dinamika Sosial Ekonomi, 21 (1) : 1-14

baku mutu bubuk kopi. Kegiatan anggota Kelompok Tani Margo Mulyo studi banding ke Puslit Koka Jember Jawa Timur dan pelatihan budidaya tanaman kopi oleh Dinas Pertanian dan Pangan Kabupaten Kulon Progo dapat dilihat pada gambar 1 dan gambar 2.

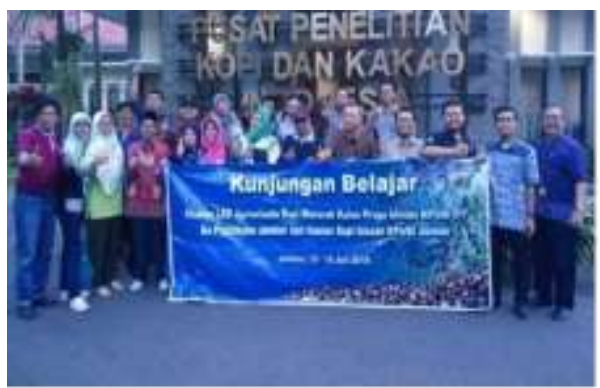

Gambar 1. Studi Banding ke Puslit Koka Jember Jawa Timur

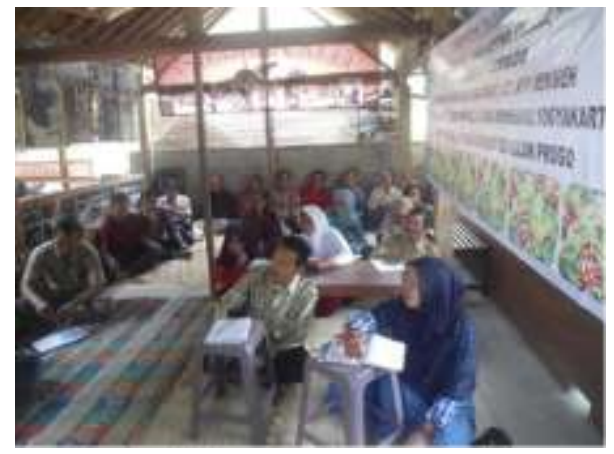

Gambar 2. Pelatihan Budidaya Tanaman Kopi oleh Dinas Pertanian dan Pangan Kabupaten Kulon Progo

Serangkaian kegiatan pendampingan yang dilakukan BI DIY ini terangkum dalam Road Maps pengembangan Local Economic Development Kopi Menoreh Kulon Progo dengan tujuan meningkatkan pertumbuhan ekonomi di daerah sekitar dengan mengangkat potensi lokal yang dimiliki, yaitu Kopi Menoreh (kopi dengan aroma khas kakao).

Bank Indonesia melalui program $L E D$ berusaha untuk memberdayakan Kelompok Tani Margo Mulyo untuk meningkatkan kesejahteraan sosial ekonomi anggotanya, dengan adanya program pemberdayaan selama terhitung sejak tahun 2018 maka pemahaman BI mengenai LED sudah berada pada tingkatan beyond 
Sudarmadi et.al., Pemahaman Bank Indonesia dan Anggota Kelompok Tani...

compliance, karena $L E D$ yang BI lakukan ini merupakan program rutin yang BI lakukan dengan berbagai penerima manfaat dari daerah lain. Menurut Badan Pusat Statistik, perkembangan UMKM yang berada di kota Palembang dilihat dari indeks produksi dari tahun 2011 sampai 2014 mengalami kenaikan dari tahun ke tahun (Ritawati dan Mubarok, 2015).

Hal ini sesuai dengan teori Wibisono (2007) yang mendefinisikan CSR sebagai tanggung jawab perusahaan kepada para pemangku kepentingan untuk berlaku etis, meminimalkan dampak negatif dan memaksimalkan dampak positif yang mencakup aspek ekonomi sosial dan lingkungan (triple bottom line). Selain itu pemahaman CSR terbagi menjadi tiga:

1. Sekedar Basa-basi dan Keterpaksaan

CSR dipraktekkan lebih karena faktor eksternal, baik karena mengendalikan aspek sosial (social driven) maupun mengendalikan aspek lingkungan (environmental driven). Dala hal ini pemenuhan tanggung jawab sosial lebih karena keterpaksaan akibat tuntutan daripada kesukarelaan.

2. Memenuhi Kewajiban (Compliance)

CSR diimplementasikan karena memang ada regulasi, hukum dan aturan yang memaksanya. Misalnya karena ada kendali dalam aspek pasar (market driven) dan adanya penghargaan-penghargaan (reward) yang diberikan oleh segenap institusi atau lembaga, misalnya CSR Award.

3. Lebih dari Sekedar Kewajiban (Beyond Compliance) atau (Compliance Plus)

Diimplementasikan karena memang ada dorongan yang tulus dari dalam (internal driven), perusahaan menyadari bahwa tanggung jawabnya bukan lagi sekedar kegiatan ekonomi untuk menciptakan profit demi kelangsungan bisnisnya, melainkan juga tanggung jawab sosial (pelatihan kelembagaan, budidaya kopi sesuai dengan standar Dinas Pertanian Kulon Progo, dan pelatihan pengolahan makanan) dan lingkungan. 
Jurnal Dinamika Sosial Ekonomi, 21 (1) : 1-14

\section{Pemahaman Anggota Kelompok Tani Margo Mulyo terhadap Program Local}

\section{Economic Development}

Anggota Kelompok Tani Margo Mulyo sebagai peserta dan penerima manfaat seperti yang diungkapkan Setiawan. dkk (2017) bahwa dalam proses pembelajaran pertanian petani adalah peserta didik. Terdapat kegiatan penyuluhan dan pelatihan. Dalam kegiatan penyuluhan ini petani diberikan informasi yang berkaitan dengan pertanian. Anggota Kelompok Tani Margo Mulyo memahami bahwa program $L E D$ yang diselenggarakan BI DIY ini merupakan program hibah, baik berupa capacity building atau pembangunan kapasitas yakni pelatihan kelembagaan, pelatihan budidaya pengolahan makanan, kemudian pembangunan sarana dan prasanara yaitu pembangunan irigasi, demplot kebun kopi, rumah produksi kopi, rumah pengering biji kopi, dan pemberian mesin pengolah kopi, serta pemberian dana dengan nominal Rp. 227.729.000. Gambar 3 dan 4 menunjukkan beberapa mesin pengolah kopi rumah pengering kopi yang diberikan BI kepada anggota Kelompok Tani Margo Mulyo.

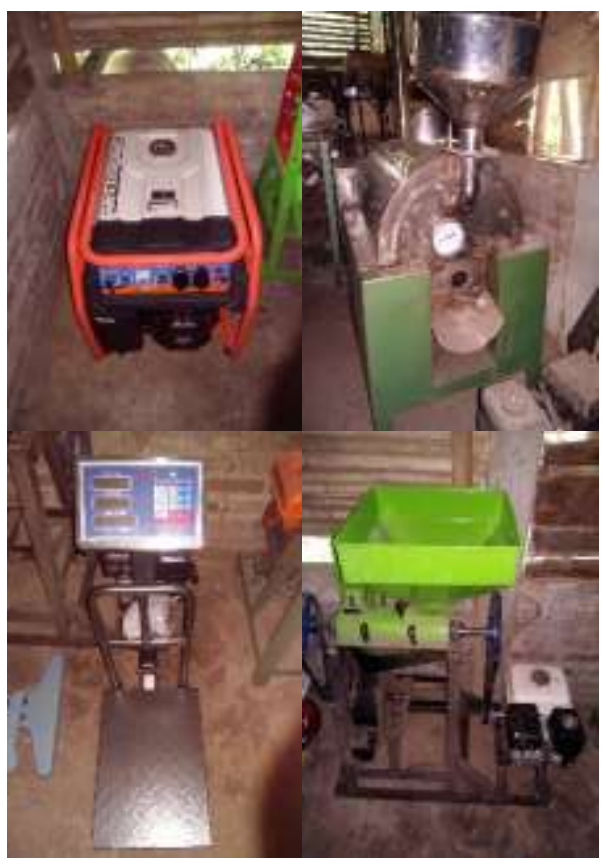

Gambar 3. Mesin-mesin Pengolahan Kopi 
Sudarmadi et.al., Pemahaman Bank Indonesia dan Anggota Kelompok Tani...

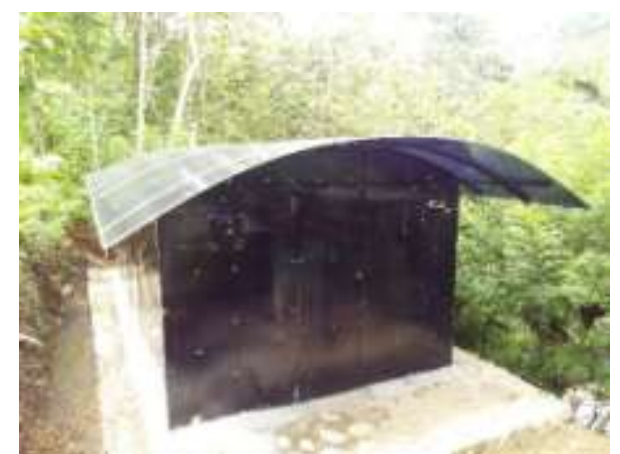

Gambar 4. Rumah Pengering Biji Kopi

Sedangkan Pengurus Kelompok Tani Margo Mulyo memahami bahwa program LED yang diselenggarakan BI DIY ini merupakan program pemberdayaan masyarakat yang ditujukan untuk mengembangkan Kelompok Tani Margo Mulyo, mewujudkan tujuan Kelompok Tani Margo Mulyo yaitu Wisata Edukasi Menoreh dan berkelanjutan. Seperti yang diungkapkan Iryana (2018) Program pemberdayaan perlu dirancang untuk berkelanjutan, sekalipun pada awalnya peran pendamping lebih dominan dibanding masyarakat sendiri. Tapi secara perlahan dan pasti, peran pendamping akan makin berkurang, bahkan akhirnya dihapus karena masyarakat sudah mampu mengelola kegiatannya sendiri. Proses pemberdayaan yang diberikan kepada Anggota Kelompok Tani Margo Mulyo dapat dilihat pada Gambar 5. 


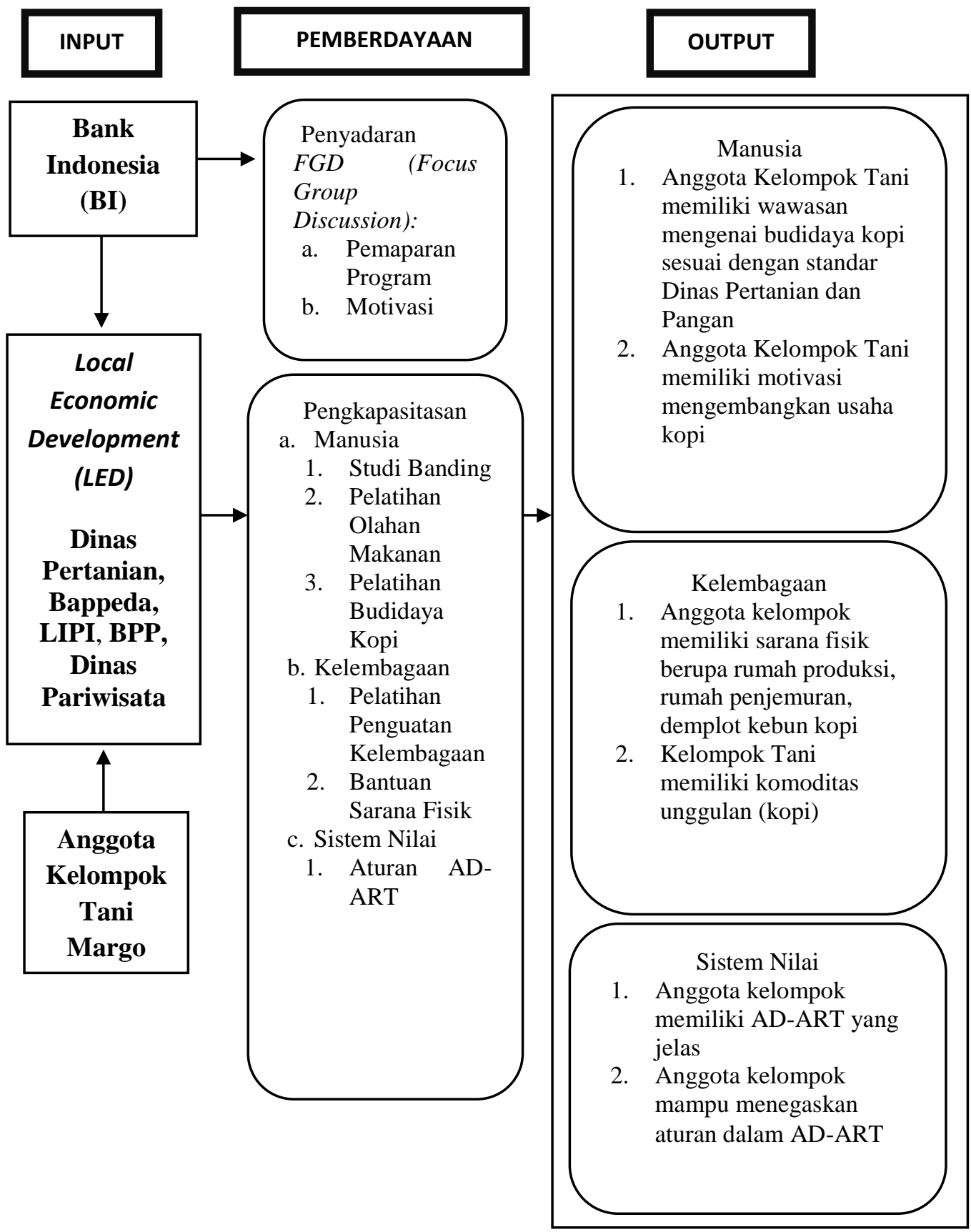

Gambar 5. Bagan Proses Pemberdayaan Kelompok Tani Margo Mulyo

Berdasarkan gambar 5, program LED yang diselenggarakan BI yang diberikan kepada Kelompok Tani Margo Mulyo dimulai dengan tahap penyadaran yang dilakukan dengan $F G D$ oleh seluruh pihak yang terkait dalam program $L E D$, kemudian dalam $F G D$ dipaparkan program yang sudah tercakup dalam Detail Engineering Design (DED) dan motivasi yang disampaikan oleh BI agar 
Sudarmadi et.al., Pemahaman Bank Indonesia dan Anggota Kelompok Tani...

Kelompok Tani Margo Mulyo menjadi mandiri serta membuat kopi menoreh semakin dikenal masyarakat luas. Dalam gambar 6 merupakan suasana $F G D$ yang dilaksanakan di gedung Bank Indonesia kantor perwakilan Yogyakarta.

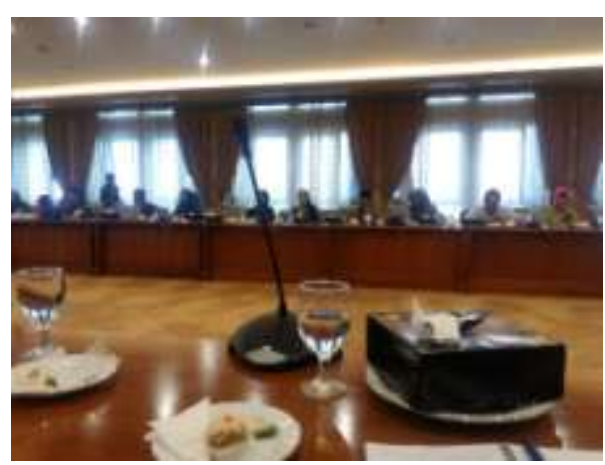

Gambar 6. FGD Program LED

Focus Group Discussion ini diikuti oleh perwakilan dari Dinas Pertanian, Bappeda, LIPI, BPP, Dinas Pariwisata, anggota Kelompok Tani Margo Mulyo, perwakilan pemuda desa Sidoharjo dan beberapa pihak yang memiliki peluang berperan dalam menjalankan program $L E D$.

Proses pemberdayaan yang dilakukan yaitu melalui penyadaran yang berupa sosialisasi dan motivasi terhadap petani sehingga petani sadar bahwa mereka perlu diberdayakan. Kemudian tahap selanjutnya adalah pengkapasitasan yang terdiri dari pengkapasitasan manusia, pengkapasitasan kelembagaan dan pengkapasitasan sistem nilai. Beberapa program yang dilakukan antara lain studi banding dan magang di Puslit Koka Jember, pelatihan budidaya kopi sesuai standar Dinas Pertanian dan Pangan dan pelatihan olahan makanan (pembuatan aneka olahan makanan selain kopi, yaitu mie ayam, gethuk dan beberapa olahan makanan lainnya). Berikut dalam gambar 7 dan 8 menunjukkan kegiatan pelatihan pengolahan makanan dan pelatihan penguatan kelembagaan. 
Jurnal Dinamika Sosial Ekonomi, 21 (1) : 1-14

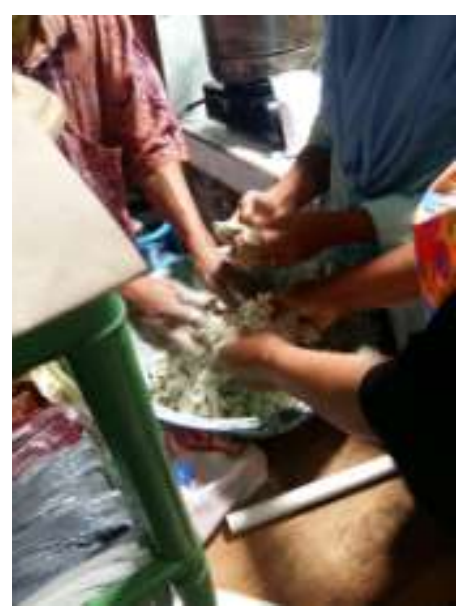

Gambar 7. Pelatihan Pengolahan Makanan

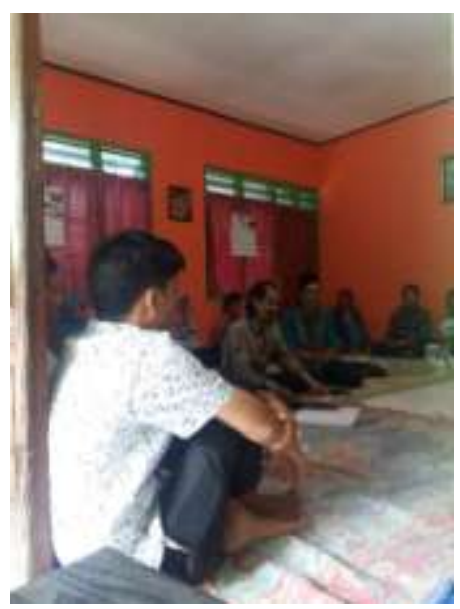

Gambar 8. Pelatihan Penguatan Kelembagaan

Proses pemberdayaan yang dilakukan BI kepada anggota Kelompok Tani Margo Mulyo dilakukan dengan tujuan membuat anggota Kelompok Tani Margo Mulyo mandiri dan perekonomian meningkat dengan memanfaatkan potensi lokal, yaitu Kopi Menoreh, hal ini sesuai dengan Mutmainna. dkk. (2016) yang menyebutkan bahwa pemberdayaan merupakan strategi untuk mengembangkan petani melalui kelompok tani untuk menjadikan kelompok tani yang kreatif dan mandiri. Dengan memberdayakan kelompok tani maka dapat menciptakan masyarakat dapat meningkatkan kemampuan kelompok tani dalam bekerja sama untuk mengembangkan usaha kelompok taninya. 
Sudarmadi et.al., Pemahaman Bank Indonesia dan Anggota Kelompok Tani...

Proses pemberdayaan yang dilakukan BI kepada anggota Kelompok Tani Margo Mulyo belum sampai kepada tahap pemberian daya, dimana anggota Kelompok Tani Margo Mulyo masih diberikan pelatihan-pelatihan dan belum diberikan kewenangan secara penuh untuk mengelola usaha mereka tersebut, namun hal tersebut belum memenuhi teori merujuk pada Wrihatnolo dan Dwidjowijoto (2007) yang membagi tiga proses pemberdayaan yaitu penyadaran, tahap pengkapasitasan dan tahap pemberian daya. Hal tersebut disebabkan karena anggota Kelompok Tani Margo Mulyo belum memiliki minat yang tinggi untuk mengembangkan lebih lanjut potensi Kopi Menoreh dalam jumlah besar sehingga partisipasi anggota Kelompok Tani Margo Mulyo cenderung naik turun hal ini didukung dengan pernyataan Sonbait dan Wambrauw (2011) yang menyebutkan bahwa partisipasi yang diharapkan adalah partisipasi aktif dari anggota sehingga akan melahirkan perasaan memiliki dari program yang akan dikerjakan bersamasama.

\section{KESIMPULAN DAN SARAN}

\section{Kesimpulan}

Pemahaman Bank Indonesia berada dalam tingkat beyond compliance atau compliance plus. Pemahaman anggota Kelompok Tani Margo Mulyo terhadap program Local Economic Development (LED) adalah program hibah.

\section{Saran}

Pemahaman Bank Indonesia terhadap program Local Economic Development sudah berada pada tahap beyond compliance sehingga Bank Indonesia sebaiknya tetap mempertahankan pemahaman tersebut agar ketika melaksanakan pemberdayaan masyarakat Bank Indonesia dapat memberikan dampak nyata dari pemberdayaan kepada penerima manfaat atau masyarakat. Pemahaman Anggota Kelompok Tani Margo Mulyo terhadap program Local Economic Development adalah program tersebut merupakan program hibah sehingga belum adanya keinginan yang kuat untuk meningkatkan kemandirian kelompok tani. 
Jurnal Dinamika Sosial Ekonomi, 21 (1) : 1-14

\section{DAFTAR PUSTAKA}

Astri, Herlina. (2012). Pemanfaatan Corporate Social Responsibility (CSR) Bagi Peningkatan Kualitas Hidup Manusia Indonesia. Jurnal CSR. 3(2). 151165.

Iryana, Asep I. (2018). Pemberdayaan Masyarakat Petani dalam Meningkatkan Kesejateraan Hidup di Kecamatan Compreng Kabupaten Subang. Jurnal Academia Praja. 1(2). 125-140

Marthin., Salinding, M. B., Akim, I. (2017). Implementasi Prinsip Corporate Social Responsibility (CSR) Berdasarkan Undang-Undang Nomor 40 Tahun 2007 Tentang Perseroan Terbatas. Jurnal jukum privat dan komersial. 1(1).111-132

Mutmainna I., Hakim L, Saleh D. (2016). Pemberdayaan Kelompok Tani Dikecamatan Marioriwawo Kabupaten Soppeng. Jurnal Administrasi Publik. 2(3). 269-283.

Setiawan, Dani Ari., Redjeki, Endang Sri., Nasution, Zuklarnain. (2017). Analisis Proses Pembelajaran dalam Konsep Pemberdayaan Kelompok Tani. Jurnal Pendidikan. 2(8). 1077-1080.

Sonbait, L.Y. dan Wambrauw, Yustina L. D. (2011). Permasalahan dan Solusi Pemberdayaan Masyarakat Melalui Program Biogas Sebagai Energi Alternatif di Kabupaten MAnokwari Papua Barat. Jurnal Ilmu Ternak. 11(2). 87-91.

Ritawati, Mubarok, N. (2015). Efektifitas Program Sosial Bank Indonesia (PSBI) Terhadap UMKM di Kota Palembang. Jurnal Ekonomi. 1(1).

Sugiyono. (2016). Metode Penelitian Kuantitatif, Kualitatif dan Kombinasi (Mixed Methods). Bandung: Alfabeta

Wibisono, Yusuf. (2007). Membedah Konsep \& Aplikasi CSR (Corporate Social Responsibility). Gresik: Fascho Publishing.

Wrihatnolo dan Dwidjowijoto. (2007). Manajemen Pemberdayaan. Jakarta: PT Elex Media Komputindo. 